The International Journal of

Urologic History $(\subset)$

www.ijuh.org

\title{
The First Two Total Cystectomies - A brief history of failed-successes
}

\author{
Harry Herr \\ From the Department of Urology, Weill Cornell Medical College New York, New York. \\ Correspondence: Section of Urology, Memorial Sloane Kettering Cancer Center, 1275 York Avenue, New York, New York; e-mail: hherr@mskcc.org
}

Introduction: Radical cystectomy is a complex surgery for bladder cancer which has undergone progressive changes for a century. The originators of the procedure required pioneering innovation and their biographies place the challenges of radical cystectomy in proper perspective.

Sources: English and German textbooks and secondary sources were analyzed.

Results: Bernard Bardenheuer (1839-1913) and Karl Pawlik (1849-1914) performed the world's first two cystectomies for bladder cancer, overcoming challenges of contemporary anesthesia, vascular control, and renal drainage.

Conclusions: The originators of radical cystectomy illustrate that true advances in surgery require bold innovation and forward thinking but also that the limitations of contemporary technology must be overcome.

Keywords: cystectomy, history

In the late 19th century, partial cystectomy was used to treat bladder tumors on rare occasions, but total removal of the whole bladder was believed to be beyond the limits of surgery. Two renowned surgeons rejected existing dogma and, when presented with challenging cases for which no other means were available, decided to risk a Blasenextirpation (Ger.: Bladder removal). The heroic story of their clinical innovation, from contemporary accounts of peers and in the surgeons' own words, demonstrate the basis for such a gewagter Eingriff (Ger.: "a daring surgical intervention").

\section{SOURCES}

We cited German works by Frederick Moll et al. as indicated, used contemporary surgical texts, translations of Bardenheuer's and Pawlik's descriptions of surgery, and photography in the public domain or cited from indicated sources.

\section{RESULTS}

The First Cystectomy. Bernhard Bardenheuer (18391913) (Figure 1, left) was a prominent German surgeon at the Cologne Citizens' Hospital in 1886 when he examined 57 year-old Theodor Baum, who suffered from locally advanced bladder cancer blocking both ureter. $(1,2)$ Bardenheuer could not palpate the tumor and established the diagnosis by the newly invented cystoscopy. He knew effective surgery was nonexistent at the time for advanced pelvic cancers, but he wrote..."I have always asked the question about bladder cancer if it would be possible to remove the whole bladder, in the cases where the entire bladder or the ureteral orifices are affected by tumor". $(3,4)$ Faced with the challenge of an incurable locally advanced bladder cancer by conventional means, "I decided and suggested to the patient removal of the tumor and perhaps the bladder, then planned to implant the ureters into the rectum."(2)

The operation took place on January 13, 1887 in the City Hospital of Cologne (Figure 2). Bardenheuer documented the operation as follows:

"Through a superficial oblique incision and cutting the outer muscle layers of the bladder wall, it appeared that one could easily separate the whole bladder and individual muscle layers from the mucosa, so that one would be able to remove the mucosal cover alone. I began to peel off the mucosa everywhere from the 

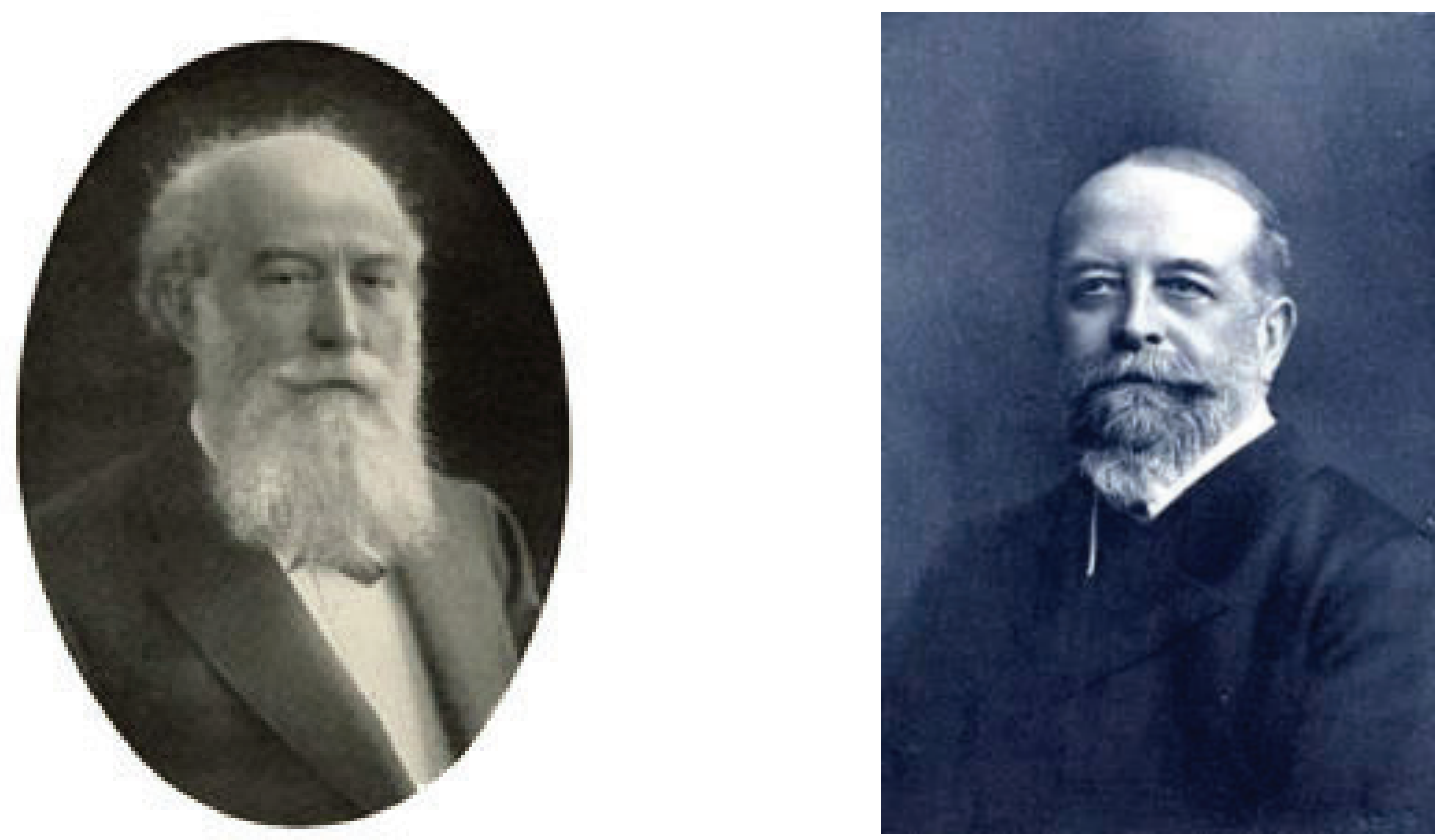

FIGURE 1 (Left) Bernard Bardenheuer (1839-1913) performed the world's first cystectomy in Cologne, Germany in 1887 (Bernard Becker Medical Library Archives, Washington University, St. Louis) (Right) Karel Pawlik (1849-1914) performed the second cystectomy in Prague a year later (Wikimedia)

muscle; this went well on the back and sides, but not the dome because here the cancer had extended far beyond the bladder wall. The right ureter was enlarged, the size of a finger ("fingerdick"), and was transected extravesically. Despite excision of the left sidewall (of the bladder), I was unable to find the left ureter, so I assumed that it was obstructed. The fundus together with the prostate was then lifted off the rectum after the urethra was severed. (The) patient had become very weak." The operation had lasted 75 minutes.

During the first days after the operation, recovery appeared hopeful, however after two weeks, Baum succumbed to uremia.

"Operation successful, patient dead". The autopsy report stated, "The left ureter was obstructed, the left kidney markedly hydronephrotic, the right (kidney) showed likewise the early stage of hydronephrosis. The wound cavity was completely closed, nowhere existed an infection."

Bardenheuer did not explain why he neglected to implant the right ureter into the rectum as he had planned and left it to drain freely into the pelvis. Moll suggests that he had to forego implanting the ureter owing to excessive bleeding encountered while removing the prostate.(3) We also do not know pathology of the bladder specimen to ascertain whether Bardenheuer may have cured his patient. Nevertheless, his first ever total cystectomy represented forward thinking and pioneering work, which opened the door for others to follow. Although he never performed another cystectomy, the next case occured two and a half years later.

The Second Cystectomy. Karel Pawlik (1849-1914) (Figure 1, right) was an Austro-Czech gynecologist working in Prague who trained in Vienna under the famed surgeon and polymath Theodor Billroth (18291894). Pawlik innovated many urologic advances including air cystoscopy.(5) Howard A. Kelly (18581943), an American gynecologist who sometimes did work in the emerging field of urology, credited Pawlik for identifying the anatomic landmarks, and for technologic innovations, that allowed for freehand ureteral catheterization.(6) Pawlik performed his first cystectomy during his tenure as Professor at the University of Prague.

"The patient (woman) came to Prof. Pawlik for the first time on June 16, 1888 on account of persistent hematuria... (At cystoscopy), he detected a thin-stalked polyp the size of a cracked almond. After creating an artificial vesicovaginal fistula, he cut out the attached stem of the polyp with thermocautery and sutured up the fistula. Complete healing followed, and the woman left the clinic July 28,1888 .(3)

"A year later, on July 11, 1889, she came again to the clinic in very weak anemic condition. For eight months 


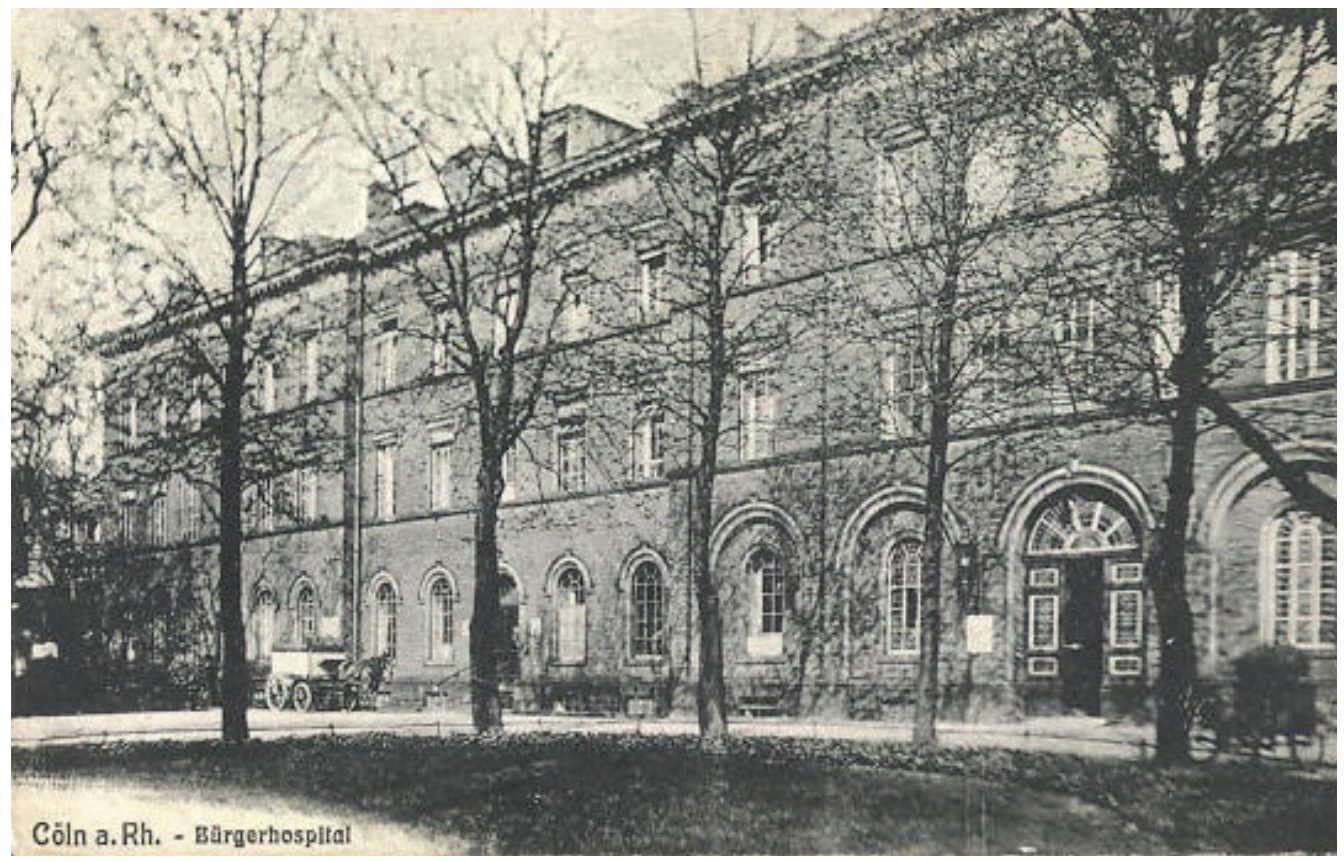

FIGURE 2. Site of the world's first cystectomy by Bardenheuer, the Kölnische Bürgerhospital an der Fleischmengergasse (City Hospital of Cologne). "The large glass window gave a view of the bare chestnut tree in the inner courtyard and the west facade of the Church of St. Cecilia" in the Neumarkt sectin of Cologne. Despite red crosses on the roof, half the building was destroyed in the air raids of 1942. (Courtesy, Friedrich H. Moll, University of Cologne, Germany)

after the operation she had felt well, then hematuria recurred without stopping. Endoscopic examination of the bladder interior showed massive, widely situated papillomas. Malignancy was confirmed through the microscope.

Pawlik conceived of performing a cystectomy in two stages with the ultimate goal of forming an orthotopic reservoir using redundant vaginal wall. The first stage occurred on August 3, 1889, when Pawlik performed a transvaginal procedure to dismember the ureters from the bladder and have them form ureterovaginal fistulas. "On August 27 the total cystectomy followed. Through a sectio alta (extraperitoneal suprapubic incision used for bladder stones)..., Pawlik mobilized the bladder down to the (bladder neck)...The anterior vaginal wall ...was split transversely and the bladder was pulled through... into the vagina and cut off at its internal orifice. The woman collapsed here but was resuscitated with a subcutaneous injection of $300 \mathrm{cc}$ of warm, physiological saline solution." The anterior and posterior vaginal walls were circumferentially sutured to the urethra using colpocleisis. Before closure, elastic ureteral catheters were introduced into both ureters through the urethra.

"The subsequent recovery was relatively good", despite the development of a pelvo-vaginal fistula, poor post-operative nutrition, and midline abdominal wound healing.

"The opening at the lower end of the abdominal wound healed first about three months after the operation; the cavity behind the symphysis and the vaginal fistula even after eight months. A second attempt to close the vagina on June 20, 1890 failed.

"On July 18, Pawlik performed a new colpocleisis in the sagittal direction reinforced with widely placed continuous level sutures. This healed down to a very fine fistula just under the urethra. Lying down the patient now held the urine for a long time; when she stands up however, it trickles down through the fistula. The woman notices (that the vaginal bladder may contain up to $400 \mathrm{cc}$ which she was)....able to spontaneously empty by contracting her perineal muscles. It will now be possible to close the small fistula and... it is very probable that the new bladder will possess sufficient continence. In any case, the woman, who a year ago had a threatening villus cancer, now was able to undertake a trip to Berlin to visit the great city. This operation, the first ever performed on a woman, has found all-around appreciation and recognition from colleagues."(7)

\section{DISCUSSION}

We can assume that the first two cystectomies were 'simple' cystectomies. Both were extraperitoneal, violated tumor margins, and did not remove perivesical fat or pelvic lymph nodes around the bladder. They were not radical cures or obeyed the principles of a formal cancer operation that we know today as a radical cystectomy. On the other hand, medical advances are appreciated in context of their unique time and place. It was nearly a century later, after all, that modern 
surgical oncologic principles began to be established. No previous surgeon had attempted to remove the whole bladder which may have been deemed a 'radical' attempt to manage incurable bulky papillary or invasive bladder cancers. The alternative was that patients were otherwise consigned to languish without treatment until their inevitable, painful deaths.

These two attempts at cystectomy, despite their patients' ultimate outcome, represent successes. Bardenheuer's surgery may have failed because of bad (i.e. advanced) disease, the lack of a urinary diversion, and antibiotic chemotherapy. Pawlik had more success partly owing to a favorable (i.e. localized) tumor and a creative viable urinary diversion which was no less than a novel, albeit primitive, orthotopic neobladder.(8) What became clear from these moments in the late 19th century was that removal of the whole bladder was feasible and sometimes necessary to cure bladder tumors, but that long-term survival was inextricably linked to successful and well-maintained diversion of the urine.

Surgical 'first' claims are common, and most are minor modifications (albeit some significant) of existing techniques. True 'firsts' in surgery, which establish a new standard of care or a basis for future advances, are, indeed, rare. Although many factors other than surgical experience and skill contribute to revolutions in surgery, the essential element is a brave patient and a visionary surgeon - an individual who possesses more talent, imagination and will than her/his contemporaries, who sees what is possible where others can't, who, despite the admonitions of influential colleagues, proceeds with an innovative, but untried operation, not for fame and fortune, but a fervent desire to help a desperate patient in need for whom contemporary treatment does not exist. Some true 'Firsts' initially fail, but if scientifically sound, most later attempts succeed and become landmarks in the history of urology. To this, the contributions of Bardenheuer and Pawlik stand out.

Significant change in medical practice comes slowly, and from the end of the 19th to the first half of the 20th century, few cystectomies were performed. The urine was diverted into the vagina, large bowel, or to the skin.9 Most attempts failed miserably, and surgeons acquired little enthusiasm for an aggressive operation associated with a greater than $50 \%$ mortality. Total cystectomy was just too dangerous, referred to "as a life-threatening operation, which for the bearer would be possessed with life-long severe, unpleasant consequences, whose assessment prohibits a final judgement."(3) Urologic textbooks warned, "that patients in general can live better without as with the operation."(3) It was not until after World War II that the modern open radical cystectomy was introduced into urologic practice as a safe (albeit still morbid) and therapeutic operation for invasive bladder cancer, thanks to the research and further attempts of Wyland Leadbetter (1907-1974), Victor Marshall (1913-2001), Willet Whitmore (1917-1995), and later Donald Skinner. all standing on the shoulders of Bernhard Bardenheuer and Karel Pawlik.

\section{CONCLUSION}

Bernard Bardenheuer and Karel Pawlik, within a year of each other, completed the first two known cystectomies for bladder cancer. Their pioneering efforts led the way for the long and unending process of improving surgery for the betterment of patients and their outcomes.

\section{REFERENCES}

1. Moll F, Dulfer R, Botel J et al: Bernhard Bardenheuer's (1839-1913) contribution to the development of modern urology. J Med Biogr 1998; 6: 11. doi: 10.1177/096777209800600102

2. Bardenheuer B: Der Extraperitoneale Explorativschnitt. Die differentielle Diagnostik der Erkrankungen des Abdomens [The Extraperironeal Exploratory. The Differential Diagnosis of Abdominal Illnesses]. Stuttgart: Ferdinand Enke 1887, pp 674-676

3. Moll F: Anfange der modernen Urochirurgie im 19. Jahrhundert. In: Streiflichter aus der Geschichte der Urologie. Edited by D Schultheiss. Berlin: Springer Verlag 2000. doi.org/10.1007/978-3-642-59647-6_2

4. Frank M, Moll F: Die Harnblase des Theodor Baum. Von kleinen Leuten und grossen Taten. In: Kolner KrankenhausgeschichtenAnonymous Cologne, Germany: Verlag des Koelnischen Stadtmuseums 2006.

5. Schultheiss D, Machtens SA, Jonas U: Air cystoscopy: the history of an endoscopic technique from the late 19th century. BJU Int 1999; 83: 571.

6. Kelly HA: Catheterization of the Ureters. Gyn Paed 1893; 6: 641.

7. Pawlik K: Ueber Blasenextirpation. Wien Med Wochenschr 1891; 41: 1816.

8. Pawlik K: 1. Über das Sondieren der Ureteren der weiblichen Blase aus freier Hand ohne vorbereitende Operation. Centralblatt für Gynäkologie 1881; 7: 1.

9. Fischel E: Total Cystectomy for Cancer - An obsolete operation? J Urol 1925; 14: 285. 